\title{
FAMILY QUALITY OF LIFE AND THE BUILDING OF SOCIAL CONNECTIONS: PRACTICAL SUGGESTIONS FOR PRACTICE AND POLICY
}

\section{Meaghan Edwards, Trevor Parmenter, Patricia O’Brien, and Roy Brown}

\begin{abstract}
Family quality of life literature suggests that families with a member with an intellectual/developmental disability frequently face major difficulties in building social connections with others. They experience low levels of social support, face challenges in community inclusion, and are at risk of social isolation. These challenges may also be faced by other types of marginalized families. Families experiencing serious illness, families experiencing intrafamily violence, and migrant families or those seeking political asylum, for example, may also become isolated and find themselves without pathways to connections with others. We present practical suggestions intended for families and professionals interested in action and intervention at the personal, community, program, and policy levels to encourage the growth of social connections and prevent isolation of families experiencing social exclusion. The suggestions will come from families with a member with a disability and the findings of a study examining the social support of families as it relates to quality of life.
\end{abstract}

Keywords: intellectual disabilities, developmental disabilities, family quality of life, policy development, practice, marginalized families, family challenges, marginalization

Meaghan Edwards $\mathrm{PhD}$ (the corresponding author) is an Instructor in Community Rehabilitation and Disability Studies, Cumming School of Medicine, University of Calgary, 3280 Hospital Drive NW, Calgary, Alberta, Canada. Email: meaghan.edwards@ucalgary.ca

Trevor Parmenter PhD is an Emeritus Professor in the School of Medicine at the University of Sydney and Adjunct Professor in the School of Rural Medicine at the University of New England, Level 1, Medical Foundation Building - K25 92-94 Parramatta Road, Camperdown NSW 2050, Australia. Email: trevor.parmenter@sydney.edu.au

Patricia O'Brien $\mathrm{PhD}$ is Professor in Disability Studies and Director, Centre for Disability Studies, University of Sydney, Level 1, Medical Foundation Building - K25 92-94 Parramatta Road, Camperdown NSW 2050, Australia. Email: patricia.obrien@sydney.edu.au

Roy Brown $\mathrm{PhD}$ is Professor Emeritus, University of Calgary, Canada, Emeritus Professor Flinders University, Australia, and Adjunct Professor at the School of Child and Youth Care, University of Victoria, PO Box 1700, STN CSC, Victoria, BC V8W 2Y2, Canada. Email: royibrown@shaw.ca 
This article is intended to be of practical use to professionals, families, and those interested in the experiences of marginalized families. The focus is upon the importance of social connections and social support to the health and positive functioning of individuals, families, and communities. In particular, the impact of a lack of social connection upon marginalized families with extra support needs, such as families with a member with a disability, will be explored. The framework and findings from the field of family quality of life (FQOL), especially as related to families with a member with a developmental or intellectual disability, will be utilized to illustrate the process and meaning of social support and social connections, which are likely to apply to other challenging situations. Practical ideas to improve access to social connections and support will be illustrated with examples drawn from the stories of families with a child with a disabling condition, recognizing that it is the family as a whole that faces these challenges. These suggestions may also have utility for a broader range of families facing marginalization, including those experiencing serious illness, families experiencing intrafamily violence, asylum seekers, and those facing stigma or exclusion in society and their communities.

\section{Social Connections and Social Support in the Health and Social Sciences}

Social connections, whether entailing emotional and practical support, the building of trusting reciprocal relationships and community, or the sharing of information and resources via social networks, are recognized by most social and health sciences as vital to the successful functioning of individuals, families, and communities. Connections and the ability to rely on others for assistance are considered to be essential aspects of what it means to be human, and have been proposed as important elements in our evolution and survival as a species (Belsky \& Simpson, 2008; Bowlby, 1973). Having positive levels of connection with others including friendships, networks, and social supports seems to be a predictor of positive mental and physical health outcomes, a facilitating element in coping and resilience, and an important indicator of the stability and security of communities. Researchers tend to view social support and connections with other people as an important part of living a life of quality (Hupcey, 1998).

Social support from family and friends has been linked to positive mental and physical health outcomes and has been suggested by some researchers to be the most consistent and important variable in individual health outcomes (House, 2001; Turner \& Turner, 2013). The World Health Organization (WHO) has asserted that being part of a social network is crucial to the health, quality of life, sense of belonging, and security of a person (Sen, Ostlin, \& George, 2007).

In the social sciences, connection with others has been an important field of study since the inception of sociology, with Durkheim (1972) suggesting that social ties seemed to be associated with lower rates of suicide. The importance of connections with others has continued to emerge in social science research with opportunities for meaningful social engagement connected to bolstering self-esteem, increasing a sense of well-being, encouraging resilience, and 
promoting a sense of community (Berkman \& Glass, 2000; Cohen, Underwood, \& Gottlieb, 2000; Cohen \& Wills, 1985). Ecological systems theory (Bronfenbrenner, 1986) recognizes the essential nature of a person's place in the social world, seeing an individual as existing within nested structures of influence from family, friends and social connections, community, and the larger policy and societal climate. This framework forms the basis for the development and design of interventions in many fields, including social work (Stormshak \& Dishion, 2002). Social support and social connections are understood and measured in various ways, but the concepts tend to include social integration and social network size and density, and to measure elements such as the length of relationships or the function and structure of the support available (Thoits, 1995).

Those studying communities and social and economic development are concerned with social connections. Social networks, social connection, and social support are a part of the concept of social capital as developed by, most notably, Putnam (2000), Coleman (1988), and Bourdieu (1986). Social capital has been framed by Putnam (2000) and Winter (2000) as social networks of reciprocity, mutual support, and trust. Social capital allows people to access support, make connections, and to work together as a community to address and resolve problems that they face in common (Stewart-Weeks \& Richardson, 1998). The ways in which individuals and families create and maintain bonds of trust and reciprocity within a community are still being studied and the topic continues to be of concern from local community development projects to international development policy papers (Bullen \& Onyx, 1999; Temple, 2001).

The meaning and mechanisms of social connection vary across research areas. Some scholars focus upon the impact of emotional support, for example, while others analyze the sharing of information and resources across complex social networks (Berkman, Glass, Brissette, \& Seeman, 2000). Social scientists from psychologists to community scholars have called for further research into how social connections are built and maintained.

\section{Social Connection, Social Support, and Marginalized Families}

Despite the well-documented importance of social connections and social support, for some people meaningful social connections are difficult to attain. A group identified in the literature to be at particular risk of social isolation is marginalized families. Marginalization tends to be characterized as an involuntary exclusion from mainstream productive activity and participation (Leonard, 1984). Such families are often those who have recently migrated or sought asylum; live in communities without supportive, safe infrastructure or services; experience poverty or homelessness; or encounter some type of social stigma due to a difference such as a disability or a distinct culture or language (Cortis, Katz, \& Patulny, 2009). Although each family is unique and root causes of marginalization and social exclusion are complex, research has found that in general most challenged families have trouble with isolation in their community and report a lack of social supports and social connections (Carbone, Fraser, 
Ramburuth, \& Nelms, 2004). Families most in need of supportive, helpful social networks and community engagement tend to be those least likely to receive these supports.

This trend is especially concerning since studies have suggested that the ability to connect with friends, neighbours, and the local community is essential to the well-being of marginalized families. The Australian Institute of Family Studies describes social support and social connection as a "potent influence in parents' lives" (Ceballo \& McLoyd, 2002, p. 1311). The perceived size and availability of parents' social networks were linked to positive family coping mechanisms when extra challenges such as marginalizing factors were experienced (Benson, 2016). The experience of social support and social connection was found to be related to reduced family stress and to contribute to resilience, as well as being associated with hardiness (Ben-Zur, Duvdevany, \& Lury, 2005; Greeff, Vansteenwegen, \& Gillard, 2012). In marginalized families, low social support has been correlated to poor home and school relationships and lower levels of educational success for children (Social Exclusion Task Force, 2007; Mackenzie, Kotch, \& Lee, 2011).

Families experiencing marginalization are often in need of extra support that may be offered through formal support services, but engagement with services is often quite low in isolated populations (Carbone et al., 2004). Families may feel that services are inflexible, insensitive to family needs, difficult to understand, or difficult to access. They may not feel listened to and may have difficulty trusting service providers (Mendoza, Katz, Robertson, \& Rothenberg, 2003). They also may have difficulties in expressing or recognizing their needs. This lack of engagement in services and low levels of social connection for marginalized families are linked to the phenomenon of social exclusion - being shut out from the social and political processes of integration into one's community (Cappo, 2002). The conceptual model of exclusion used by the Social Exclusion Knowledge Network commissioned by the WHO includes economic, political, social, and cultural dimensions, with these exclusionary processes creating a continuum characterized by an inappropriate distribution of resources and unequal access to capabilities and rights (Popay et al., 2010).

Social exclusion is fundamentally about a lack of social connectedness and participation (McDonald, 2011; Saunders, Naidoo, \& Griffiths, 2007). Almost all definitions of social exclusion include a lack of social connectedness and social support, and a lack of social participation. Social inclusion, in contrast to social exclusion, can be conceptualized as domains of opportunity, including structured opportunities to connect with friends, neighbours, and the local community. McDonald (2011) suggested, "Children and families need to feel connected to and supported by their community, especially when they face obstacles and challenges. They also need to feel a sense of belonging and to feel as if their voice will be heard" (p. 3). 


\section{Social Connection, Social Support, and Families with a Member with an Intellectual or Developmental Disability}

Researchers have called for further work into how to promote social connections and enhance social support for marginalized, socially excluded families (e.g., Burton, Boyle, Harris, \& Kagen, 2007; Davy, 2016; Hayes, Gray, \& Edwards, 2008). In the field of disability, specifically intellectual and developmental disabilities, research has been conducted with families examining their access to support from other people. Intellectual disability is the presence of significant differences or limitations both in intellectual functioning and adaptive behaviour appearing before the age of 18. Developmental disability is an umbrella term that often includes intellectual disability and also includes disabilities affecting development such as cerebral palsy (Schalock et al., 2010). Since families with a member with an intellectual or developmental disability typically experience marginalization and social exclusion, some learning and some practical suggestions from this field, specifically the FQOL, are presented in the following sections in the hope that families, professionals, and policy makers concerned with other types of marginalization may recognize common challenges and solutions. Quality of life and FQOL researchers have suggested that the principles and concepts of the field are generalizable to other areas and may be applicable and useful in a variety of settings (Brown \& Faragher, 2014).

\section{Family Quality of Life and Social Support Findings}

FQOL research in the current article is concerned with listening to and responding to the needs of families with a member with an intellectual or developmental disability. The field looks at various aspects of family life with the express goal of giving families a voice in determining which aspects of life are most important and which areas need further support (Isaacs et al., 2007). A good quality of life for families has been suggested by Zuna, Brown, and Brown (2014) to exist when "families consider their lives to be happy and fulfilling, all members are healthy, they have a safe place to live, have a stable income, enjoy their lives together, have opportunities to learn and improve, benefit from the community supports and resources, and experience fulfilling social relationships with others" (p. 162). The FQOL Survey-2006 is a tool that attempts to measure the quality of families' lives (Brown et al., 2006). The domains examined on the FQOLS-2006 are Health, Financial Well-Being, Family Relationships, Support from Other People, Support from Services, Leisure, Values, Careers and Preparing for Careers, and Community Interaction. The survey has been translated into 25 languages and results have been published in over 15 countries.

Families around the world in such countries as Australia, Canada, Israel, Italy, Japan, Nigeria, and Malaysia have responded in similar ways to FQOL measures, despite differing cultural and economic contexts (Brown, Kyrkou, \& Samuel, 2016). The domain measuring social support, Support from Other People, has been given consistently low scores by families, and is often reported as having the lowest satisfaction rating of the life areas measured on the FQOLS2006 (Ajuwon \& Brown, 2012; Rillotta, Kirby, Shearer, \& Nettelbeck, 2012; Samuel, Rillotta, \& 
Brown, 2012). Research indicates that a large proportion of families report few opportunities to receive or seek out support from other people; few efforts are reported as being made by families to obtain further support from other people, and the levels of support attained seem to be unsatisfactory. FQOL studies also suggest that many families are isolated and do not want to burden others with their needs, leading to a situation in which those who need the most help may be unwilling or unable to ask for it (Brown, Anand, Fung, Isaacs, \& Baum 2003). In view of the low satisfaction ratings for social support, it is of great concern that social support seems to be positively related to the overall quality of life of the family (Kresak, Gallagher, \& Kelley, 2014; Meral, Cavkaytar, Turnbull, \& Wang, 2013). Despite the importance of social support for health, resilience, and inclusion in the community, families with a member with an intellectual or developmental disability seem to find social support difficult to obtain.

\section{Findings from an In-Depth Multiple Case Study}

An investigation into the meaning and process of social support for families was carried out in Sydney, Australia using the FQOL framework in a multiple case study approach involving six families having varying reported levels of social connections. The design was based upon previous FQOL findings and sought to explore the meaning of social connections and the barriers and facilitators to building them. Findings suggested that enhancing social connections was linked to the development of emotional and practical support, the building of reciprocal relationships, access to information and resources, and the creation of pathways to collective action (Edwards, 2016). Families who reported having rich social networks tended to be supported by friends, communities, and social services that actively reached out and took a strong role in organizing practical and emotional help. This assistance included organizing formal and informal circles of support for the person with disability and the family, helping with shopping and child care, and providing access to clear, accurate information on available services for the person with disability and the caregivers. This active, well-planned support also appeared to be strengthened by supportive, family-centered program and policy development that included and respected the voice of families.

A model was developed based on the findings in the context of wider FQOL and social support literature, suggesting that social connections could be expanded for families through supportive friends and neighbours, structured opportunities for connection, trusted formal allies and services, an inclusive community, and family-centred policy. The model was suggested to be relevant to enhancing the connections of families who have been marginalized in any of a variety of ways (Edwards, 2016). The model has gone through initial testing and the results are being prepared for publication.

The stories of two of the family participants in the larger case study are outlined below to illustrate some of the challenges and successes families with a member with an intellectual or developmental disability may experience in the process of building and maintaining social connections. These families' stories are not meant to represent the experiences of every family 
with a member with an intellectual or developmental disability, but the narratives are reasonably typical of research findings in the field. Identifying details in the following family stories have been changed to protect the confidentiality of participants.

Maria's Family: Maria is a woman who has three grown children, the oldest of whom is in her late twenties and has Down syndrome with physical health complications of a heart condition and digestive issues. Since Maria's husband passed away five years ago, she has become increasingly socially isolated. While she was once an active member of her community with strong social ties, she relates that time spent seeking out appropriate disability-related services and caring for her daughter have meant that her friendships have fallen away over the years. She has not felt comfortable asking others for help. In addition, she experiences her own health issues, which have made pursuing a career very difficult. She has found little support in the community and says she no longer attempts to participate in community events since people do not seem to understand her family and do not welcome her daughter. She has no one she can trust to take care of her daughter. Services have proved difficult to access and are seen as untrustworthy. She expresses confusion about recent changes in disabilityfocused legislation and services. Maria expresses ideas about participating in her community such as joining advocacy groups or volunteering but is uncertain as to how this might come about. She identifies herself as lonely but has no plans to try to improve her social connections since this has proved difficult and timeconsuming in the past. She has been unsuccessful in building social connections.

Sarah's Family: Sarah is a mother of two children, the youngest of whom is a son in his early teens who has cerebral palsy and an intellectual disability. She has had to quit her job in order to care for her son and spends a great deal of time advocating on his behalf. She has a number of allies who assist her in this including her extended family and the administration staff of her son's school. She has managed, with the help of a community organization, to set up a circle of support for her son. This circle is made up of her friends from university, work, and the local community. The circle helps Sarah and her son make important decisions and plan for the future in addition to getting together just to socialize and have fun. She also works together with other families with a member with a disability to organize events and fundraising and lobby the government for better services for people with disabilities. She has neighbours who have reached out to assist her and these neighbours offer practical support when needed such as assisting in yard maintenance or cooking occasional meals for Sarah's family. Despite her successes in attaining and maintaining social connections, Sarah suggests that her family continues to experience social isolation at times and encounters a sense of exclusion at certain community events and community 
organizations like sports teams. Despite ongoing challenges, her social connections have allowed her to take collective action to improve services, find support in other people, and build strong relationships in her community. Sarah indicates, however, that these social connections were not easy to create or maintain, and that the efforts she makes to enhance connection for her entire family have left her exhausted and at times disillusioned.

Maria and Sarah's stories illustrate some of the challenges and successes families, especially mothers, may find in building connections for their families. Despite the difficulties, it seems that social connections are useful and important.

The importance of connecting theory and practice has been recognized in the field of FQOL and such a connection has been strengthened through the use of family stories and experiences (i.e., Turnbull, Brown, \& Turnbull, 2004). A set of practical suggestions for organizations, community support workers, and policy makers on supporting families to enhance social connections and increase access to social support and community resources may be useful and timely (Zuna et al., 2014; Edwards, 2016). The suggestions below are based on findings and theory in the field, and are intended to be of use to professionals and families. The suggestions should be explored in further detail in future research in order to examine the impact, efficacy, and practicality of the approaches.

\section{Practical Suggestions for Supporting Family Members to Connect with Others}

Although efforts to make social connections by a main caregiver may be an important aspect of connection, the FQOL literature has found that efforts to seek out social support are infrequent. People may be prevented from making efforts by ill-health, exhaustion, negative emotions, and lack of time (Brown et al., 2003). This seems to be a significant barrier that could be overcome through more organized efforts on the part of those who support families, such as neighbours and friends. It may be that people in these families' lives need to be informed that families may not necessarily ask for needed support, and without proactive attempts at connection from other people may not receive it. A public education campaign or investments in smaller community campaigns informing community groups of this phenomenon might encourage people to reach out and help others. Research suggests that investment in local organizations and programs tends to increase the social capital of an entire community, encouraging a climate in which people are more likely to connect with friends and neighbours (Bullen \& Onyx, 1999).

Despite the clear difficulty with making efforts to reach out, advocacy or support organizations often place the onus upon families to do the reaching out or to manage these connections. Although some organizations may offer support in doing this, a structure of supporting families through assisting the caregivers in a proactive way might provide greater assistance here. The assistance might include making child care available during peer support meetings, encouraging the development of parent advocacy groups, and actively encouraging 
participation of families in program planning. Whitaker (2013) found that, while mothers of children with intellectual and developmental disability looked for support for their children with "dogged determination", they also needed strong support from a responsive service climate and an inclusive community.

Opportunities for peer mentoring set up and led by parents who have gone through the experience and understand what it takes to go from isolation to connection may also be of assistance here. Such an approach has been useful in areas where parent peer-support programs have been implemented (Turnbull, Turnbull, \& Kyzar, 2009). O’Brien (1989) has written about the challenges of building pathways to relationships for people with extra support needs. Suggestions include increasing opportunities for interactions with neighbours, and increasing places in the community where people can interact, prioritizing interactive leisure opportunities. There is also a suggestion that services and funding structures focus upon and recognize the importance of increasing social contacts.

Brown, Corbigo, and Taylor (2015) also recognized the need for service-led and serviceorganized parent groups that offer trustworthy, safe support for the child with disability and siblings, allowing the parent to have a break from the caring role and network with other parents. McArthur and Faragher (2014) have suggested that families who are isolated need to be assisted with accessing the social supports that could make a positive difference for themselves and their children. Their research suggested the use of "targeted" services to work alongside informal networks to provide practical and emotional support at the local level. Further, partnering among formal programs to build informal networks such as playgroups and parent groups in normal, safe, non-stigmatizing places will provide increased chances for social connectedness.

\section{Practical Suggestions for Building Trusting Relationships between Services and Families}

A need for trustworthy, responsive services has been recognized in the literature and suggestions have been made to assist service providers in moving to a place of mutual cooperation and respect with families. Blue-Banning, Summers, Frankland, Lord Nelson, and Beegle (2004) suggested six components of family-professional partnerships aimed at increasing connection: communication, skills, respect, commitment, equality, and trust.

Under the component of communication, the need to listen and to be honest and clear is foundational to building a strong relationship with families. Simple listening skills such as attention and eye-contact during meetings have been suggested by parents as areas that could be improved. Frequent, accessible contact in familiar settings also appear to be important to family members. Many families, according to FQOL literature, do not appear to have experienced this type of open, respectful relationship with service providers (Brown et al., 2003). Efforts on the part of formal supporters towards a more family-centred practice may assist in building the trust necessary for families to share their needs and experiences. A positive formal support climate may encourage families to participate in service-led structured opportunities to connect with others, like peer-led training or networking events. Trusting services to provide reliable support 
through respite services, day services, or an external supported-living situation, may enable caregivers to have time to pursue connections of their own. Family capacity-building has also been put forward as a useful approach for service providers. This empowering approach aims to work with parents to increase knowledge and skills, thus improving families' confidence and competence (Dunst, Bruder, \& Espe-Sherwindt, 2014).

Researchers have also suggested that formal support workers, in addition to providing family-centred services that respond to family-determined need, may become community connectors rather than caregivers only, thus enabling people to become active, accepted members of the community (Sherwin, 2010). Brown and colleagues (2015) suggested that in order for service providers to enable inclusion and create opportunities for connections to develop the vision and mission of the organization, they must go beyond rhetoric and state in practical ways how they will enhance social inclusion for the people and families they support. Brown et al. (2016) emphasized the importance of a collaborative approach to providing appropriate support to families across agencies in a supportive policy environment. This would require an ongoing, thorough, systematic evaluation framework of support services and systems that responds to concerns and adapts services and supports accordingly. Schalock and Verdugo (2014) have suggested and outlined such a framework in detail (pp. 19-34; see also Schippers, Zuna, \& Brown, 2015).

\section{Practical Suggestions for Creating More Inclusive Communities}

Those who study inclusive communities have suggested that relationships and social connections are the glue that holds communities together and a lifeline to happier lives and more satisfying existences (Amado, 1990). Sherwin (2010) recognized that a shift towards inclusion for people with intellectual disability and their families requires genuine efforts on the part of leaders towards creating an attitude shift at a local grassroots level so that community members might become aware of the gifts and contributions of people with disabilities and their families. Practical suggestions for building inclusive communities may involve investment in organizations to help set up community groups allowing connections to develop. Investment in community centres that host peer mentoring, group classes, or courses, and investment in support of neighbourhood leaders, may also be helpful. These leaders could be helped to mobilize communities to be more connected, fostering inclusive communities (Block, 2008; Chaskin, 2001).

Investments in places outside the home, areas where people can get together, share, and have conversations on neutral ground, allowing relationships to build, have also been suggested in the literature on inclusive communities (Oldenburg, 1997). Others have suggested that assetbased development may assist in allowing people in a community to connect in a strengths-based framework, where relationships are able to thrive and valued social roles are encouraged (Kretzmann \& McKnight, 1993). Researchers have also suggested that fostering relationships may result in positive social action through such methods as purposeful network building in 
communities (Westoby \& Owen, 2010). These ideas encourage environments in which marginalized families are included more meaningfully in the community.

\section{Practical Suggestions for Involving Families in Building Policy and Practice}

A focus upon families, communities, and relationship building strategies may assist those at risk of isolation to become connected in meaningful ways. The connections that have the potential to be built among families may open up pathways towards positive change, ultimately allowing families to design the supports best suited to their needs and strengths. Families were an important part of the deinstitutionalization and normalization movements in the field of intellectual and developmental disability (Samuel et al., 2012), and great potential still exists for families to be well-supported, highly effective agents of social change. Parmenter (1992) suggested that social policy needs to recognize the importance of the empowerment of families and investment in communities in the creation of opportunities for all citizens to live lives of quality and move towards political activism and social change. Especially relevant to the findings is his call to provide resources to informal networks, intentional communities, and social connections that are the lifeblood of genuine communities (Parmenter, 2004).

Supportive policy allowing families to begin to build essential social connections does not seem to be developing. In Canada, for example, among families with a child up to age 14 with a disability including physical, developmental, and intellectual disability, only $44 \%$ reported receiving formal assistance from government-funded agencies, and 54\% of parents, usually mothers, of children with disabilities reported that caring for their child with a disability meant they were unable to participate meaningfully in employment (Behnia \& Duclos, 2003). Without adequate respite and support it is difficult to imagine how families can find time and energy to begin to build those essential social connections and participate actively in communities. Additionally, families often report a lack of information about service changes and available support services in their communities (Brown et al., 2003). Government investment in the accessible communication of policy and programs might be of great benefit here.

The Canadian government has committed to developing the Canadians with Disabilities Act 2018, promising to promote equality of opportunity and increase the inclusion and participation of Canadians who have physical, developmental, and intellectual disabilities and their families (Government of Canada, 2017). Consultations with organizations, advocacy groups, and people with disabilities and their families have recently concluded; it will not become clear how inclusive, accessible, and respectful this process has been until the data collected from the consultations are made public. It can only be hoped that such consultations and eventual policy adjustments will begin to reverse some of the feelings of isolation and marginalization experienced by people with intellectual and developmental disability and their families. Policy needs to be developed in collaboration with government bodies including provinces, states, and other levels of regional government and should be reflected in the 
availability of a range of socially oriented support services that are capable of being matched to individual and family needs.

The practical solutions mentioned in the preceding sections were useful to families like Maria's and Sarah's and may be of value to other families facing challenges with establishing and maintaining useful connections in the community. Some of the suggestions are applied below to illustrate the potential impact on individual families.

Maria's family (possible actions): While Maria might currently feel quite lonely and isolated, these trends could possibly be reversed with targeted and intentional changes and investments, such as the following, with the aim of Maria and her family members becoming healthy, active, and well-connected citizens in their community:

- Investment and education in community organizations and programs in Maria's neighbourhood to facilitate social engagement and encourage people to connect with friends and neighbours.

- Peer-led supports for families in a respectful professional environment.

- A parent group in which Maria might take a strong advocacy role could lead to the strengthening of connections, the lessening of loneliness, and a strong sense of purpose and collective action.

- Service-provider training of staff in how to build trusting, mutually respectful relationships with parents.

- Greater access to information about programs and policies to facilitate Maria's interest in advocacy.

- A priority on involving parents in the development of policy in a more transparent way.

Sarah's family (successes and possible actions): While Sarah reports feeling much more connected than Maria, she has had to sacrifice a great deal, including her career, in order to take care of her son while building and maintaining her connections. She seems to have benefited greatly from proactive friends and neighbours in her well-connected community but still reports feeling stigmatized and isolated at times. Although Sarah has found a great deal of success, her exhaustion and burden might be somewhat alleviated with the development of government policy that supports families through adequate respite, well-designed community programs, and the valuing of family members' expertise. Some practical suggestions for Sarah's family include:

- Further investment in education and community programs within Sarah's local community may assist her and her family to become more included.

- Support for advocacy programs and peer support networks might help build sustainable connections within their community.

- Employment opportunities for Sarah to act as a trainer in advocacy and family support. 
The practical solutions offered in this article are specifically connected to families with a member with an intellectual or developmental disability but may have application wherever families have been socially excluded. Experiences of isolation, disengagement from services, stigma in the community, and a lack of power in important decision-making and policy seem to be a part of the lives of families in a variety of settings. Targeted strategies at the family, community, and policy levels may be of benefit to any family experiencing exclusion from meaningful civic and social participation.

\section{Conclusion}

This article suggests that social connection, social support, and the building of social networks is vital to all people, yet may be of particular importance to families experiencing various forms of marginalization. Research results in the FQOL framework regarding the social connections and social support of marginalized families with a member with an intellectual or developmental disability were presented, along with two brief family stories illustrating the challenges in building and maintaining social connections. Practical suggestions for assisting families in connecting with others were put forward in the hopes that such practical ideas might be applied with other families experiencing marginalization. We suggest that with targeted investment and planning, marginalized families may become connected in such a way that they may access information, resources, pathways to collective action, reciprocal connections, and emotional and practical support. It seems that in order to bring about change and to empower these families, continuous research is needed to uncover and help ensure the best ways to mobilize pathways to connections, ultimately moving towards a more inclusive society for all families. Much of this research requires a close interaction between researchers and the researched. Collaboration within an inclusive model is an important ingredient in future research. 
International Journal of Child, Youth and Family Studies (2018) 9(4): 88-106

\section{References}

Ajuwon, P. M., \& Brown, I. (2012). Family quality of life in Nigeria. Journal of Intellectual Disability Research, 56(1), 61-70. doi:10.1111/j.1365-2788.2011.01487.x

Amado, A. N. (1990). Friends: A manual for connecting persons with disabilities and community members. St Paul, MN: Human services Research and Development Center. Retrieved from https://files.eric.ed.gov/fulltext/ED363985.pdf

Behnia, B., \& Duclos, E. (2003). Statistics Canada Participation and Activity Limitation Survey 2001: Children with disabilities and their families. Ottawa, ON: Statistics Canada. Retrieved from http://www.statcan.gc.ca/pub/89-585-x/pdf/4228545-eng.pdf

Ben-Zur, H., Duvdevany, I., \& Lury, L. (2005). Associations of social support and hardiness with mental health among mothers of adult children with intellectual disability. Journal of Intellectual Disability Research, 49(1), 54-62. doi:10.1111/j.1365-2788.2005.00662.x

Benson, P. R. (2016). The longitudinal effects of network characteristics on the mental health of mothers of children with ASD: The mediating role of parent cognitions. Journal of Autism and Developmental Disorders, 46(5), 1699-1715. doi:10.1007/s10803-016-2699-3

Belsky, J., \& Simpson, J. A. (2008). Attachment theory within a modern evolutionary framework. In J. Cassidy \& P. R. Shaver (Eds.), Handbook of attachment: Theory, research, and clinical applications, (2nd ed., pp.131-157), New York, NY: Guilford.

Berkman, L. F., \& Glass, T. (2000). Social integration, social networks, social support, and health. In L. F. Berkman \& I. Kawachi (Eds.), Social epidemiology (pp. 137-173). New York, NY: Oxford.

Berkman, L. F., Glass, T., Brissette, I., \& Seeman, T. E. (2000). From social integration to health: Durkheim in the new millennium. Social Science \& Medicine, 51(6), 843-857. doi:10.1016/S0277-9536(00)00065-4

Block, P. (2008). Community: The structure of belonging. San Francisco, CA: Berrett-Koehler.

Blue-Banning, M., Summers, J. A., Frankland, H. C., Lord Nelson, L., \& Beegle, G. (2004). Dimensions of family and professional partnerships: Constructive guidelines for collaboration. Exceptional Children, 70(2), 167-184. doi:10.1177/001440290407000203

Bourdieu, P. (1986). The forms of capital. In J. G. Richardson (Ed.), Handbook of theory and research for the sociology of education (pp. 241-258). New York, NY: Greenwood Press.

Bowlby, J. (1973). Attachment and loss, vol. II: Separation. New York, NY: Basic Books. 
Bronfenbrenner, U. (1986). Ecology of the family as a context for human development: Research perspectives. Developmental Psychology, 22(6), 723-724. doi:10.1037/0012-1649.22.6.723

Brown, I., Anand, S., Fung, W. L. A., Isaacs, B., \& Baum, N. (2003). Family quality of life: Canadian Results from an international study. Journal of Developmental and Physical Disabilities, 15(3), 207-230. doi:10.1023/A:1024931022773

Brown, I., Brown, R. I., Baum, N. T., Isaacs, B. J., Myerscough, T., Neikrug, S. ... Wang, M. (2006). Family Quality of Life Survey: Main caregivers of people with intellectual disabilities. Toronto, ON: Surrey Place Centre. Retrieved from http://www.surreyplace.ca/research/current-research/about-the-international-family-qualityof-life-project/surveys/

Brown, R. I., Corbigo, V., \& Taylor, W. D. (2015). Quality of life and social inclusion across the lifespan: Challenges and recommendations. International Journal of Developmental Disabilities, 61(2), 93-100. doi:10.1179/2047386914Z.00000000092

Brown, R. I., \& Faragher, R. (2014). Quality of life-Challenges from the field of intellectual and developmental disabilities. In R. I. Brown \& R. Faragher, (Eds.), Quality of life and intellectual disability. Knowledge application to other social and educational challenges (pp. 37-54). New York, NY: Nova Science.

Brown, R. I., Kyrkou, M. R., \& Samuel, P. S. (2016). Family quality of life. In I. L. Rubin, J. Merrick, D. E. Greydanus, \& D. R. Patel (Eds.), Health care for people with intellectual and developmental disabilities across the lifespan (pp. 2065-2082). New York, NY: Springer.

Bullen, P., \& Onyx, J. (1999). Social capital: Family support services and neighbourhood and community centres in NSW. New South Wales, Australia: Local Community Services Association.

Burton, M., Boyle, S., Harris, C., \& Kagan, C. (2007). Community psychology in Britain. In S. M. Reich, M. Riemer, I. Prilleltensky, \& M. Montero (Eds.), International community psychology. Boston, MA: Springer.

Cappo, D. (2002, November). Social inclusion, participation and empowerment. Presented at the Australian Council of Social Service ACOSS Congress, Hobart, Tasmania.

Carbone, S., Fraser, A., Ramburuth, R., \& Nelms, L. (2004). Breaking cycles, building futures: Promoting inclusion of vulnerable families in antenatal and universal early childhood services. Melbourne, Australia: Victorian Government Department of Human Services.

Ceballo, R., \& McLoyd, V. C. (2002). Social support and parenting in poor, dangerous neighborhoods. Child Development, 73(4), 1310-1321. doi:10.1111/1467-8624.00473 
International Journal of Child, Youth and Family Studies (2018) 9(4): 88-106

Chaskin, R. J. (2001). Building community capacity: A definitional framework and case studies from a comprehensive community initiative. Urban Affairs Review, 36(3), 291-323. doi: $10.1177 / 10780870122184876$

Cohen, S., Underwood, L. G., \& Gottlieb, B. H. (2000). Social support measurement and intervention: A guide for health and social scientists. Oxford, UK: Oxford University Press.

Cohen, S., \& Wills, T. A. (1985). Stress, social support, and the buffering hypothesis. Psychological Bulletin, 98(2), 310-357. doi:10.1037/0033-2909.98.2.310

Coleman, J. S. (1988). Social capital in the creation of human capital. American Journal of Sociology, 94, S95-S120. doi:10.1086/228943

Cortis, N., Katz, I., \& Patulny, R. (2009). Engaging hard-to-reach families and children: Stronger families and communities strategy 2004-2009 [FaHCSIA occasional paper no.26]. Canberra, Australia: Department of Families, Housing, Community Servcies and Indigenous Affairs.

Davy, L. (2016, March). Governing personal autonomy: The NDIS, individualisation, and the place of people with intellectual disability and their families. Sociology departmental seminar presentation, University of Sydney, Sydney, Australia.

Dunst, C. J., Bruder, M. B., \& Espe-Sherwindt, M. (2014). Family capacity-building in early childhood intervention: Do context and setting matter? The School Community Journal, 24(1), 37-48.

Durkheim, E. (1972). Selected writings. Cambridge, UK: Cambridge University Press.

Edwards, M. E. (2016). Expanding connections: Exploring social support within a family quality of life framework (Doctoral dissertation). Retrieved from The University of Sydney eScholarship Repository. http://hdl.handle.net/2123/15652

Government of Canada. (2017). Rights of people with disabilities. Retrieved from https://www.canada.ca/en/canadian-heritage/services/rights-people-disabilities.html

Greeff, A. P., Vansteenwegen, A., \& Gillard, J. (2012). Resilience in families living with a child with a physical disability. Rehabilitation Nursing, 37(3), 97-104. doi:10.1002/RNJ.00018

Hayes, A., Gray, M., \& Edwards, B. (2008). Social inclusion: Origins, concepts and key themes. Canberra, Australia: Australian Government.

House, J. S. (2001). Social isolation kills, but how and why? Psychosomatic Medicine, 63(2), 273-274. doi:10.1097/00006842-200103000-00011 
Hupcey, J. E. (1998). Clarifying the social support theory-research linkage. Journal of Advanced Nursing, 27(6), 1231-1241. doi:10.1046/j.1365-2648.1998.01231.x

Isaacs, B. J., Brown, I., Brown, R. I., Baum, N., Myerscough, T., Neikrug, S., ... Wang, M. (2007). The International Family Quality of Life Project: Goals and description of a survey tool. Journal of Policy and Practice in Intellectual Disabilities, 4(3), 177-185. doi:10.1111/j.1741-1130.2007.00116.x

Kresak, K. E., Gallagher, P. A., \& Kelley, S. J. (2014). Grandmothers raising grandchildren with disabilities: Sources of support and family quality of life. Journal of Early Intervention, (1)3-17. doi:10.1177/1053815114542506

Kretzmann, J., \& McKnight, J. (1993). Building communities from the inside out: A path toward finding and mobilizing a community's assets. Chicago, IL: ACTA Publications.

Leonard, P. (1984). Personality and ideology: Towards a materialistic understanding of the individual. London, UK: MacMillan.

MacKenzie, M. J., Kotch, J. B., \& Lee, L.-C. (2011). Toward a cumulative ecological risk model for the etiology of child maltreatment. Children and Youth Services Review, 33(9), 16381647. doi:10.1016/j.childyouth.2011.04.018

McArthur, M., \& Faragher, R. (2014). Children in families with complex needs. International Public Health Journal, 6(2), 199-211.

McDonald, M. (2011). What role can child and family services play in enhancing opportunities for parents and families? Exploring the concepts of social exclusion and social inclusion. Melbourne, Australia: Australian Institute of Family Studies.

Meral, B. F., Cavkaytar, A., Turnbull, A. P., \& Wang, M. (2013). Family quality of life of Turkish families who have children with intellectual disabilities and autism. Research and Practice for Persons with Severe Disabilities, 38(4), 233-246. doi:10.1177/154079691303800403

Mendoza, J., Katz, L. G., Robertson, A. S., \& Rothenberg, D. (2003). Connecting with parents in the early years. Champaign, IL: Early Childhood and Parenting Collaborative, Children's Research Center, University of Illinois.

O'Brien, J. (1989). What's worth working for? Leadership for better quality human services. Syracuse, NY: The Center on Human Policy, Syracuse University.

Oldenburg, R. (1997). The great good place: Cafés, coffee shops, community centers, beauty parlors, general stores, bars, hangouts, and how they get you through the day. New York, NY: Marlowe. 
Parmenter, T. R. (1992). Quality of life of people with developmental disabilities. In N. W. Bray (Ed.), International review of research in mental retardation (pp. 246-288). New York, NY: Academic Press.

Parmenter, T. R. (2004). Family quality of life: Implications for policy. In A. P. Turnbull, R. H. Turnbull, \& I. Brown (Eds.), Families and persons with mental retardation and quality of life: International perspectives (pp. 265-298). Washington, DC: American Association on Mental Retardation.

Popay, J., Escorel, S., Hernández, M., Johnston, H., Mathieson, J., \& Rispel, L. (2010). Understanding and tackling social exclusion. Journal of Research in Nursing, 15(4), 295297. doi: $10.1177 / 1744987110370529$

Putnam, R. D. (2000). Bowling alone: The collapse and revival of American community. New York, NY: Touchstone.

Rillotta, F., Kirby, N., Shearer, J., \& Nettelbeck, T. (2012). Family quality of life of Australian families with a member with an intellectual/developmental disability. Journal of Intellectual Disability Research, 56(1), 71-86. doi:10.1111/j.1365-2788.2011.01462.x

Samuel, P., Rillotta, F., \& Brown, I. (2012). The development of family quality of life concepts and measures. Journal of Intellectual Disability Research, 56(1), 1-16. doi:10.1111/j.1365$\underline{2788.2011 .01486 . x}$

Saunders, P. G., Naidoo, Y., \& Griffiths, M. (2007). Towards new indicators of disadvantage: Deprivation and social exclusion in Australia. Sydney, Australia: Social Policy Research Centre.

Schalock, R. L., Borthwick-Duffy, S. A., Bradley, V. J., Buntinx, W. H., Coulter, D. L., Craig, E. M., \& Reeve, A. (2010). Intellectual disability: Definition, classification, and systems of supports (11th ed.). Washington, DC: American Association on Intellectual and Developmental Disabilities.

Schalock, R. L., \&Verdugo, M. (2014). Quality of life as a change agent. In R. I. Brown \& R. M. Faragher (Eds.), Quality of life and intellectual disability: Educational and social contexts. New York, NY: Nova Science.

Schippers, A., Zuna, N., \& Brown, I. (2015). A framework for an integrated process for improving quality of life. Journal of Policy and Practice in Intellectual Disabilities, 12(3), 151-161. doi:10.1111/jppi.12111

Sen, G., Ostlin, P., \& George, A. (2007). Unequal unfair ineffective and inefficient. Gender inequity in health: Why it exists and how we can change it (Final report to the WHO Commission on Social Determinants of Health). doi:10.1080/17441690801900795 
Sherwin, J. (2010). Leadership for social inclusion in the lives of people with disabilities. The International Journal of Leadership in Public Services, 6, 84-93.

Social Exclusion Task Force. (2007). Reaching out: Think family. Analysis and themes from the Families At Risk Review. London, UK: Cabinet Office. Retrieved from: http://webarchive.nationalarchives.gov.uk/+/http:/www.cabinetoffice.gov.uk/media/cabinet office/social_exclusion_task_force/assets/think_families/think_families.pdf

Stewart-Weeks, M., \& Richardson, C. (1998). Social capital stories: How 12 Australian households live their lives. Sydney, Australia: Centre for Independent Studies.

Stormshak, E. A., \& Dishion, T. J. (2002). An ecological approach to child and family clinical and counseling psychology. Clinical Child and Family Psychology Review, 5(3), 197-215. doi:10.1023/A:1019647131949

Temple, J. R. (2001). Growth effects of education and social capital in the OECD countries. Historical Social Research / Historische Sozialforschung, 27(4 (102), 5-46.

Thoits, P. A. (1995). Stress, coping, and social support processes: Where are we? What next? Journal of Health and Social Behaviour, 35(Extra issue), 53-79. doi:10.2307/2626957

Turnbull, A. P., Brown, I., \& Turnbull, H. R. (Eds.). (2004). Family quality of life: An international perspective. Washington, DC: American Association on Mental Retardation.

Turnbull, A. P., Turnbull III, H. R., \& Kyzar, K. (2009). Family-professional partnerships as catalysts for successful inclusion: A United States of America perspective. Revista de Educación, 349, 69-99.

Turner, J. B., \& Turner, R. J. (2013). Social relations, social integration, and social support. In C. S Aneshensel, J. C. Phelan, \& A. Bierman (Eds.), Handbook of the sociology of mental health (pp. 341-356). New York, NY: Springer. doi:10.1007/978-94-007-4276-5 17

Westoby, P., \& Owen, J. (2010). The sociality and geometry of community development practice. Community Development Journal, 45(1), 58-74. doi:10.1093/cdj/bsp005

Whitaker, L. (2013). Being the bottom line: Mothers' experiences of fostering networks that will support their son or daughter with disabilities. (Doctoral dissertation). Retrieved from The University of Sydney eScholarship Repository. https://ses.library.usyd.edu.au/handle/2123/9480

Winter, I. S. (2000). Social capital and public policy in Australia. Melbourne, Australia: Australian Institute of Family Studies.

Zuna, N. I., Brown, I., \& Brown, R. I. (2014). Family quality of life in intellectual and developmental disabilities: A support-based framework to enhance quality of life in other families. In R. I. Brown, \& R. Faragher (Eds.), Quality of life and intellectual disability. Knowledge application to other social and educational challenges (pp. 91-119). New York, NY: Nova Science. 